\title{
Isolated Langerhans cell histiocytosis of the vulva: a case report and review of the literature
}

\author{
Christine Beneder • Annette Kuhn • \\ Jeannine ImObersteg $\cdot$ Karl Beer • \\ Achim Fleischmann • Michael David Mueller
}

Received: 13 July 2007 / Accepted: 15 October 2007 / Published online: 23 November 2007

(C) Springer-Verlag 2007

\begin{abstract}
Isolated Langerhans cell histiocytosis (LCH) of the female genital tract is very rare. A review of the literature revealed that only 15 cases of primary vulvar LCH have previously been published in the English literature. We describe an additional case of confined vulvar LCH. A 49-year-old woman presented with an ulcerous lesion that turned out to be LCH confined to the vulva only. After surgical excision, four recurrences followed, which were treated again by surgery. After the fourth recurrence, adjuvant radiotherapy was applied. When the fifth recurrence occurred, only surgical excision was performed, and the patient has now been disease-free for 51 months. There are no standard treatment options for this rare disease. The most effective treatment options still remain elusive. In our case in the end surgery proved to be effective.
\end{abstract}

Keywords Vulvar Langerhans cell histiocytosis .

Treatment options

C. Beneder $\cdot$ A. Kuhn $\cdot$ J. ImObersteg $\cdot$ M. D. Mueller Department of Gynaecology and Obstetrics, Inselspital Bern, Bern, Switzerland

K. Beer

Department of Radio-Oncology, Inselspital Bern,

Bern, Switzerland

\author{
A. Fleischmann \\ Bern, Switzerland \\ M. D. Mueller ( $₫)$ \\ Frauenklinik Inselspital, \\ CH-3001 Bern, Switzerland \\ e-mail: michel.mueller@insel.ch
}

Department of Pathology, Bern University,

\section{Introduction}

Langerhans cell histiocytosis ( $\mathrm{LCH}$ ), also known as histiocytosis $\mathrm{X}$, is a rare disorder of histiocyte proliferation with histiocytes which are functionally defective in their antigen-presenting ability. The clinical picture varies greatly, ranging from mild to life-threatening. Most often the disease affects children, and when it occurs in older patients, groin involvement is quite common [1]. Genital LCH as the only manifestation of this disease is very unusual. Initially, Lane and Smith reported LCH in a 6year-old child in 1939 [2]. We describe a case of primary vulvar LCH and review the current literature of this diagnostically and therapeutically challenging disease.

\section{Case report}

A 49-year-old Caucasian woman, gravida 2, para 2, attended colposcopy clinic for vulvar pruritus. A physical examination revealed a nodular lesion of $5 \mathrm{~mm}$ on the left vulva (Fig. 1). Regional lymph nodes were not enlarged. The lesion was biopsied and histological findings revealed histiocytic proliferation including cells with broad cytoplasm and a kidney-shaped nucleus as well as clusters of eosinophils (Fig. 2). Immunohistochemical stains using antibodies against $\mathrm{CD} 1 \mathrm{a}$ and $\mathrm{S}-100$ protein were positive in histiocytic cells (Fig. 3). These results were consistent with the diagnosis of LCH.

Clinical staging including chest X-ray, bone scan and computed tomography of the thorax, abdomen and pelvis did not reveal any evidence of disease beyond the vulva. According to these findings, the patient was diagnosed with LCH affecting the vulva only. A complete surgical excision 


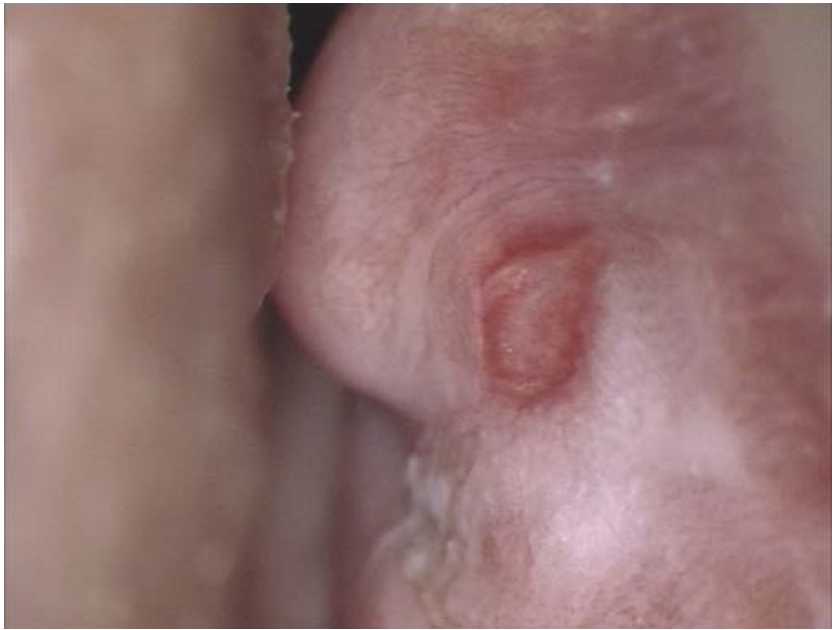

Fig. 1 Uncharacteristic presentation of the vulvar LCH lesion

was performed; the margins were free of disease with a safety margin of more than $10 \mathrm{~mm}$.

Three months later a similar lesion of the same size was excised from the right vulva and histopathological examination confirmed recurrent LCH with margins free of disease. Only 5 weeks later, two ulcerated lesions (both $2 \mathrm{~mm}$ in size) appeared on the left vulva. It proved to be recurrent LCH that was again surgically excised with margins free of disease.

During the following 10 weeks, the patient had two consecutive local recurrences, both on the left vulva, $2 \mathrm{~mm}$ in size, that were surgically removed. Since prior treatments had been unsuccessful we decided to take a more aggressive approach and started adjuvant radiotherapy with 34 Gray that was locally applied on the right and left vulva. The patient did not tolerate it well complaining of dysaesthesia and pruritus but the ulcers disappeared after radiotherapy.

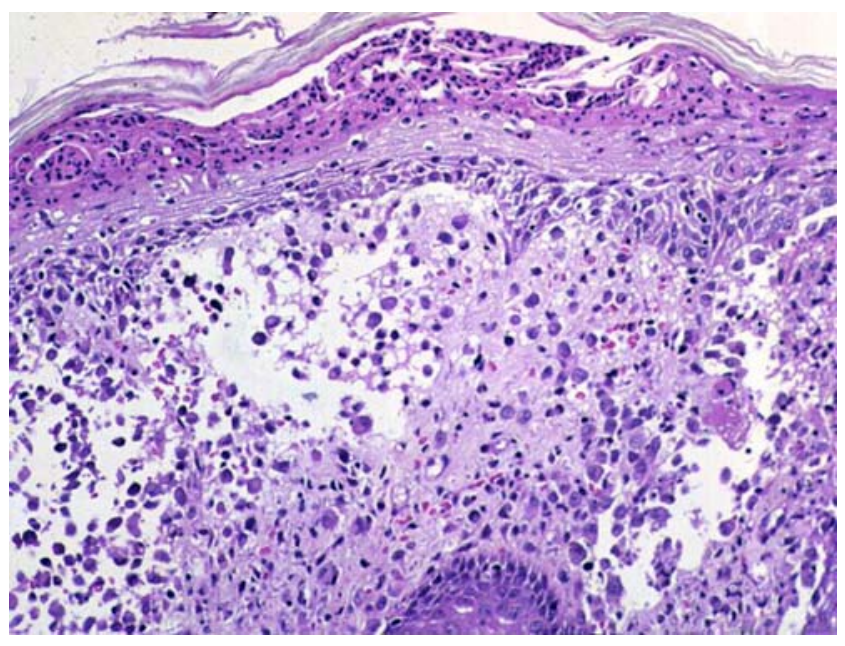

Fig. 2 Langerhans cells are histiocytes with broad cytoplasm and a kidney-shaped nucleus along with clusters of eosinophils (H\&E, 100×)

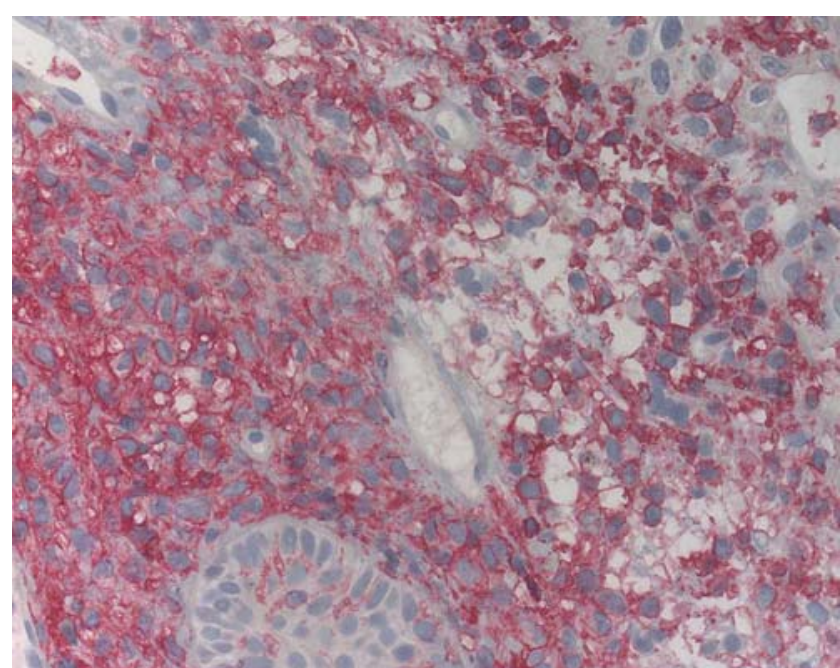

Fig. 3 Primarily membraneous staining of histiocytes with CD1a monoclonal antibody

However, 14 months later, a vulvar LCH lesion was surgically treated again and since then the patient has been without further recurrences for the past 51 months.

\section{Discussion}

$\mathrm{LCH}$ is a very rare disease, which was initially categorized into the clinical subtypes of eosinophilic granuloma, HandSchüller-Christian, or Letteres-Siwe disease, depending on the site and degree of severity [3]. Later, these were found to be different manifestations of a single disease named histiocytosis X [4]. Recently this classification has changed to $\mathrm{LCH}$, in recognition of the primary cell involved.

The pathogenesis of most histiocytoses remains unclear. A possible cytokine-related pathway [5] and a potential role of granulocyte-macrophage-colony stimulating factor (GMCSF) [6] have been suggested.

There are four distinct patterns of LCH involvement in the female genital tract: (1) pure genital LCH, in which the disease is limited to the genital tract only, (2) genital tract LCH with subsequent multiorgan involvement, (3) oral or cutaneous $\mathrm{LCH}$ with subsequent genital and multiorgan involvement, and (4) diabetes insipidus with organ involvement [7].

It is unclear why some patients are affected at the mucosa or skin only while others present with a widespread disease. There is no correlation between histological findings and the outcome of the genital lesions. Complete regression, partial improvement, persistent lesions and recurrences were found in all the cases described so far. Genital LCH can be the first presentation of systemic disease as described by Padula et al. [8]. According to the literature, $33 \%$ of isolated vulvar $\mathrm{LCH}$ subsequently disseminated [7]. 
Localized lesions of LCH are very unusual and should be differentiated by a tissue biopsy from other dermatologic disorders such as diaper rash, seborrhoea dermatitis, eczema, genital tuberculosis and sexually transmitted diseases (syphilis, herpes and granuloma inguinale). Several neoplastic processes can also resemble $\mathrm{LCH}$, including squamous cell carcinoma, malignant melanoma, sarcoma and Paget's disease of the vulva.

As in our patient, the macroscopic and colposcopic aspect of the lesions were unspecific as were the clinical symptoms.

The diagnosis of LCH is performed by tissue biopsy only. The routine evaluation should include serum electrolytes and chest X-ray, CT of the abdomen and pelvis, and a bone scan.

Since the very first case of primary vulvar LCH described in 1939 by Lane et al. [2], a total of 15 cases have been published in the English literature. Table 1 summarizes the cases, clinical presentations and treatment options of all cases. Because of the paucity of data, there is no standard recommendation for the management of vulvar $\mathrm{LCH}$. The treatment is not well defined and is highly individualized. One difficulty is the unpredictability of the course of LCH.

Treatment regimens have primarily included surgery, radiotherapy and chemotherapy. Other forms of treatment have also been used including topical corticosteroids, topical nitrogenated mustard, thalidomide, or combined therapy with varying results. Axiotis et al. [7] suggest treating genital lesions initially by complete excision, but fifty percent of the patients with genital LCH relapsed after surgery [19]. This is what happened to our patient, too. After three recurrences that were all surgically removed, we performed a local radiotherapy to avoid systemic side effects but still to allow for a more aggressive approach. A combined forum of gynaecologists, oncologists, pathologists and radio-oncologists discussed and decided on the treatment options.

Yet 14 months after radiotherapy another recurrence occurred and surgery was again performed. Since then the patient has been disease-free for the past 51 months. The patient does not have any complaints and is very satisfied. Apart from the case described by Axiotis et al. [7], this is the longest follow-up reported in literature.

Determining the success of therapy is restricted by the limited follow-up information in the majority of studies previously reported. Most of the patients experienced recurrences after their initial treatment, and all these recurrences were vulval.

We performed wide surgical excision and the margins were always free of pathologic cells. Despite the patient having three recurrences, we consider radical vulvectomy as unnecessary in LCH as it is a very radical surgical approach and there is no support in the published data that the outcome is improved after radical vulvectomy.

The superior outcome with the use of thalidomide [15] may be explained by its action on tumour necrosis factor alpha.

Chemotherapy for multisystem disease is beneficial [20], but there are few data referring to the use of chemotherapy for very localized disease. Systemic treatment with vincristine did not clear up the lesions of the patient described by Solano et al. [13], and after a surgical excision was performed, the patient remained cured. The patient that was treated according to the LCH II protocol with vinblastine and prednisone by Mottl et al. [21] relapsed as well after 8 months and received a second-line treatment

Table 1 Cases reported in literature of primary Langerhans cell histiocytosis of the vulva

\begin{tabular}{|c|c|c|c|c|c|c|c|c|}
\hline Report & Age & Clinical presentation & Excision & Radio-therapy & Chemotherapy & Others & Response & $\begin{array}{l}\text { Outcome } \\
\text { (months) }\end{array}$ \\
\hline Weidmann [9] & Unknown & Ulcers & + & - & - & - & PR & LTF \\
\hline Rose [10] & 50 & Ulcers & - & + & - & - & PR & LTF \\
\hline Axiotis et al. [7] & 85 & Ulcers & - & - & - & Corticosteroid & No response & LTF \\
\hline Voelklein et al. [11] & 36 & Ulcers & - & + & - & - & $\mathrm{CR}$ & NEOD (12) \\
\hline Savell et al. [12] & 76 & Erythematous plaques & - & - & + & - & $\mathrm{CR}$ & NEOD (8) \\
\hline Solano et al. [13] & 40 & Erythematous plaques & + & - & + & - & $\mathrm{CR}$ & NEOD (18) \\
\hline Pather et al. [14] & Unknown & Ulcers & + & - & - & - & $\mathrm{CR}$ & NEOD (24) \\
\hline Santillan et al. [15] & 33 & Nodular lesion & + & + & - & Thalidomide & $\mathrm{CR}$ & NEOD (5) \\
\hline \multirow[t]{2}{*}{ Dietrich et al. [16] } & 41 & Nodular lesion & + & + & + & - & $\mathrm{CR}$ & LTF \\
\hline & 29 & Nodular lesion & + & + & - & Corticosteroid & PR & LTF \\
\hline \multirow[t]{2}{*}{ Padula et al. [8] } & 31 & Ulcers & + & + & - & Thalidomide & $\mathrm{CR}$ & NEOD (36) \\
\hline & 52 & Ulcers & - & + & - & - & $\mathrm{CR}$ & NEOD \\
\hline Venizelos et al. [17] & 64 & Ulcers & + & + & - & - & $\mathrm{CR}$ & NEOD (22) \\
\hline Ishigaki et al. [18] & 65 & Ulcers & + & - & - & - & $\mathrm{CR}$ & NEOD (12) \\
\hline Mlyncek et al. [4] & 63 & Ulcus & + & - & - & - & $\mathrm{CR}$ & NEOD (12) \\
\hline Present report & 49 & Nodular lesion and ulcers & + & + & - & - & $\mathrm{CR}$ & NEOD (41) \\
\hline
\end{tabular}

$C R$ Complete response, $P R$ partial response, $L T F$ lost to follow-up, NEOD no evidence of disease 
with 2-chlorodeoxyadenosine. Eighteen months later she still has no sign of recurrence. According to RodriguezGalindo [22], 2-chlorodeoxyadenosine is a good option for the treatment of recurrent LCH.

The use of radiotherapy is also very controversial. A retrospective study about the use of radiotherapy in multisystem disease describes successful applications as single treatments or in combination with other therapies [23], but again there are few data about its use in local LCH. The patient described by Santillan et al. [15] relapsed after radiotherapy, as did our patient.

\section{Conclusion}

LCH should be considered when diagnosing and treating vulvar lesions. Isolated vulvar LCH has the potential for aggressive clinical behaviour either as local recurrence or as disseminated disease. The absence of controlled studies and the lack of standard diagnostic evaluation criteria have impeded therapeutic progress. There are no standard treatments, but we consider surgery as the best option with the fewest side effects and recommend it as first- and secondline treatment in patients with vulvar LCH.

\section{References}

1. Prignano F, Domenici L, Carli P et al (1999) Langerhans cell histiocytosis of the vulva: an ultrastructural study. Ultrastuct Pathol 23:127-132

2. Lane CW, Smith MG (1939) Cutaneous manifestations of chronic (idiopathic) lipoidosis (Hand-Schuller-Christian) disease. Arch Derm Syphilol 39:617-644

3. Lichtenstein L (1953) Histiocytosis X: integration of eosinophilic granuloma of bone, Letterer-Siwe disease and Schuller-Christian disease as related manifestations of a single nosologic entity. Arch Pathol 56:84-102

4. Mlyncek M, Uharcek P, Duransky D (2006) Vulvar Langerhans cell histiocytosis: a case report. Acta Obstetr Gynecol 85:753-761
5. Kannurakis G, Abbas A (1994) The role of cytokines in the pathogenesis of Langerhans cells histiocytosis. Br J Cancer 23 (Suppl):S37-S40

6. Emile JF, Freitag S, Andy P et al (1995) Expression of GM-CSF receptor by Langerhans cell histiocytosis cells. Virchows Arch 427:125-129

7. Axiotis CA, Merimo JM, Duray PH (1991) Langerhans cell histiocytosis of the female genital tract. Cancer 67:1650-1660

8. Padula A, Medeiros LJ, Silva EG et al (2004) Isolated vulvar Langerhans cell histiocytosis: report of two cases. Int J Gynecol Pathol 23:278-283

9. Weidman FD (1947) The "eosinophilic granulomas" of the skin. Arch Derm Syphilol 55:155-175

10. Rose PG, Johnston GC, O'Toole RV (1984) Pure cutaneous histiocytosis X of the vulva. Obstet Gynecol 64:58-90

11. Voelklein K, Horny HP, Marzusch K et al (1993) Primary Langerhans cell histiocytosis of the vulva. Gynecol Obstet Invest 36:189-190

12. Savell V, Hanna R, Benda JA et al (1995) Histiocytosis X of the vulva with a confusing clinical and pathologic presentation. A case report. J Reprod Med 40:323-326

13. Solano T, Espana A, Sola J et al (2000) Langerhans cell histiocytosis on the vulva. Gynecol Oncol 78:251-254

14. Pather S, Moodley JM, Bramdev A (2001) Isolated Langerhans cell histiocytosis of the vulva: a case report. J Obstet Gynaecol Res 27:111-115

15. Santillan A, Montero JA, Kavanagh JJ et al (2003) Vulvar Langerhans cell histiocytosis: a case report and review of the literature. Gynecol Oncol 91:241-246

16. Dietrich EJ, Laucirica R et al (2004) Langerhans cell histiocytosis of the vulva: two case reports. J Low Genit Tract Dis 8:147-149

17. Venizelos ID, Mandala E, Tatasiou ZA et al (2006) Primary Langerhans cell histiocytosis of the vulva. Int J Gynecol Pathol 25 (1):48-51

18. Ishigaki H, Hatta N, Yamada M et al (2004) Localised vulvar Langerhans cell histiocytosis. Eur J Dermatol 14:412-414

19. Montero AJ, Diaz-Montero CM, Malpica A et al (2003) Langerhans cell histiocytosis of the female genital tract: a literature review. Int J Gynecol Cancer 13:381-388

20. Ladisch S, Gadner H (1994) Treatment of Langerhans cell histiocytosis-evolution and current approaches. Br J Cancer 23 (Suppl):41-46

21. Mottl H, Rob L, Stary J et al (2007) Langerhans cell histiocytosis of vulva in adolescent. Int J Gynecol Cancer 17:520-524

22. Rodriguez-Galindo C, Kelly P, Jeng M et al (2002) Treatment of children with Langerhans cell histiocytosis with 2-chlorodeoxyadenosine. Am J Hematol 693:179-184

23. Olschewski T, Seegenschmiedt MH (2006) Radiotherapy of Langerhans cell histiocytosis: results and implications of a national patterns-of-care study. Strahlenther Onkol 182(11):629-634 